\title{
The Turkish Mathematical Society
}

\author{
Betül Tanbay (Bogaziçi University, Istanbul, Turkey) and Attila Aşkar (Koç University, Istanbul, Turkey)
}

The Turkish Mathematical Society (TMD) is a Turkish organisation dedicated to the development of mathematics in Turkey. Its members are either individual mathematicians living in Turkey or Turkish mathematicians living abroad, adding up to more than 800 . The society seeks to serve mathematicians particularly in universities, research institutes and other forms of higher education. In Turkey, there are more than a hundred mathematics departments, with around 2,000 faculty members, 30,000 undergraduates and 6,500 graduate students. In 2016, Turkish mathematicians published 2,300 articles in international media covered by SCI and secured an h-factor of 96. This is representative of the annual productivity.

The Turkish Mathematical Society was founded in 1948 by eminent researchers of Istanbul University and Istanbul Technical University. The governing body of the TMD is its General Assembly, consisting of all its full members. The General Assembly meets every two years and appoints the Executive Committee members, who are responsible for the running of the society. The TMD became a full member of the IMU in 1960 and was raised to Group II in 2016. It became a member of the EMS in 2008 and joined MASSEE in 2014. The society is located in Istanbul and has also, since 1992, had a branch in Ankara.

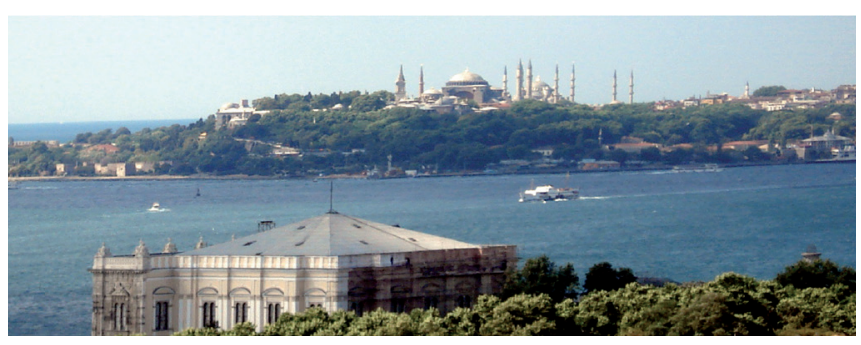

View from the terrace of the building of the TMD offices.

For the last 30 years, an annual symposium has been held in different cities and universities of the country. Each year, hundreds of academicians attend these symposia to collaborate over research and benefit from lectures presented by researchers who are selectively invited by a Scientific Advisory Committee. Through the organisation of special sessions, young researchers are given the opportunity to present their theses, giving them a professional platform for discussing their ideas.

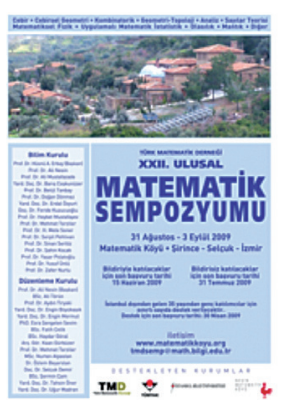

The announcement of the 22nd National Symposium organised in the Nesin Mathematical Village.

The society takes part in the organisation of the Caucasian Mathematics Conference (CMC) and, in August 2017, the second CMC was held in Van, Turkey. The TMD is an institutional member of the Silkroad Mathematical Center in Beijing and its president is a member of the Steering Committee.

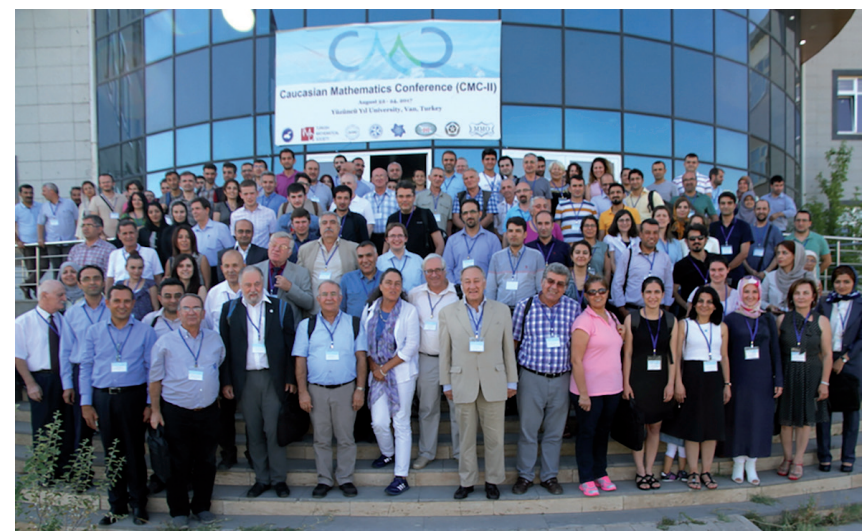

CMC-II, Van, 22 August 2017.

The only financial source of the TMD used to be the modest membership fees. In the last four years, through a project called MAD (Matematik Araştırma Dostları, i.e. Friends of Mathematical Research), a group of civil societies and individuals, convinced of the significance of a mathematical society, has been formed and has allowed the TMD to support more than 40 conferences, symposia, workshops, summer schools and youth activities in mathematics in the country (http://tmd.org.tr/mad2014-17-raporu/). In particular, the MAD-Youth Fund, again donated by a civil society, has supported five youth workshops at four universities attended by hundreds of undergraduates from throughout Turkey.

A cooperation with the Institute of Oberwolhfach and the Istanbul Center for Mathematical Sciences (IMBM)

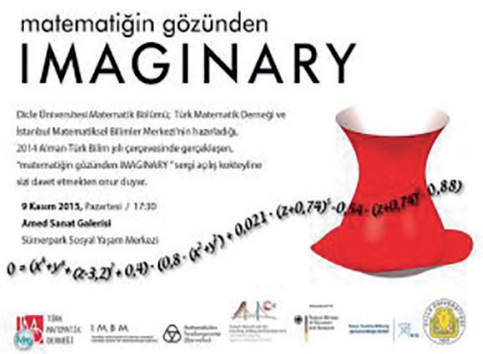

The announcement of the Diyarbakir IMAGINARY exhibition in November 2015.

The TMD offers four fellowships a year to undergraduates in mathematics, with the goal of encouraging talented youth as well as bringing the importance of this field to the attention of society at large.

A popular quarterly mathematics magazine Matematik Dünyası has been published since 1991. It sells over 


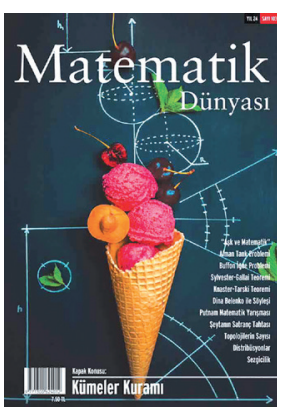

An issue of the popular magazine Matematik Dünyast.
10,000 copies per issue and is very popular with high school and undergraduate students. The magazine is designed to encourage students of all ages to pursue activities and careers in the mathematical sciences. Successive issues are dedicated to specific subjects covering contemporary advancements in mathematics.

Professional associations come about when a critical mass forms in a community. Leaving aside the individual efforts of exceptional talent in the distant past, we can see the beginning of organised efforts with the foundation of the Royal School of Naval Engineering in 1773, during the time of the Ottoman Empire. A significant turning point for formal mathematics education in Turkey was in 1830, when the "Madrassa" was transformed into a "University", later to be called Imperial University in 1900. With the energies and modernisation efforts of the new Turkish Republic in 1923, the formation of Istanbul University and Istanbul Technical University followed in 1933.

There have been two western interactions pertaining to the sciences in general and mathematics in particular. The first was the famous Einstein letter to the Turkish President Atatürk in 1933. This letter described the difficulties regarding academic freedom in Europe (with perhaps worse things to follow) and that there were many European scientists and scholars interested in coming to Turkish universities. Indeed, during the period 19331945, more than 200 German scholars (of which 15 were involved with mathematics and science) joined Turkish universities. Among the mathematicians, von Mises, Prager and Horninger left the most positive legacies. The second interaction was the report by Courant and Born on the formation of an Institute of Mathematics à la Göttingen in Istanbul. It is sad that the recommendations of this report were followed only partially and the necessary funds were not allocated.

With the efforts of the new generation of mathematicians, educated mostly in Western Europe with the support of special fellowships from the young Turkish Republic, a critical mass was forming in Turkey, resulting in the formation of the Turkish Mathematical Society in 1948. One of the first presidents of the TMD was Cahit Arf, whose picture and equation on the 10 lira banknote makes us proud and happy.

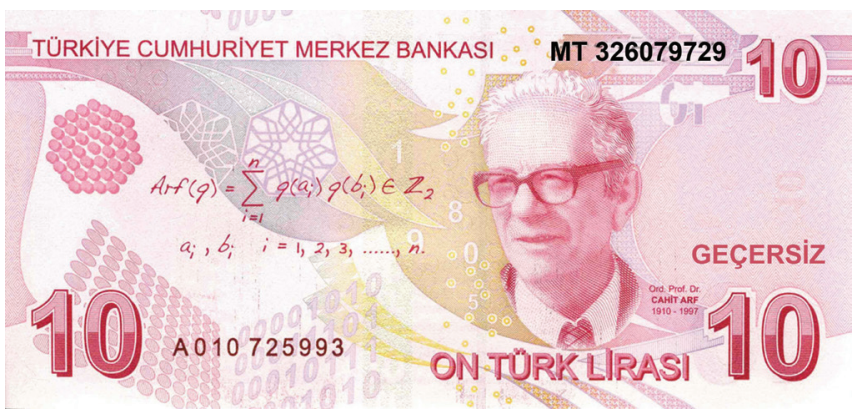

The 10 lira banknote, with Cahit Arf's photo and the Arf equation.
The TMD is also proud to have been an institution capable of renewal and continuity at the same time. Past board members still actively work for the society, whilst many young researchers have become members of the board. Over the past 20 years, the society has put particular importance on international relations and it has been represented at most meetings and assemblies of organisations such as the IMU and the EMS. We believe in the importance of global mathematical cooperation for a healthy and peaceful development of humanity.

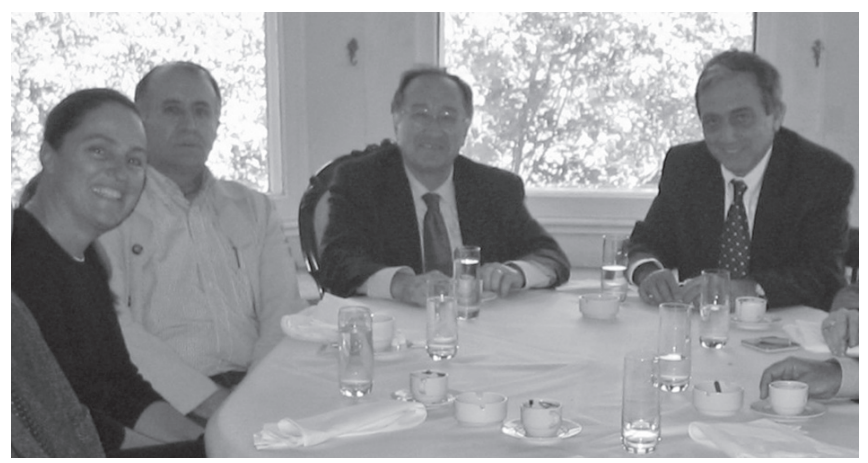

The last four presidents of the TMD from left to right: Betuil Tanbay (2010-2016), Ali Ülger (2008-2010), Attila Aşkar (2016-), Tosun Terzioğlu (1989-2008).

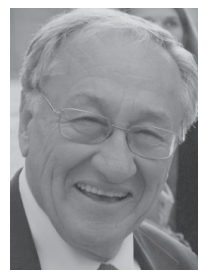

Attila Aşkar is currently the president of the Turkish Mathematical Society and a professor of applied mathematics at Koç University in Turkey, where he served as president from 2001 to 2009. He held academic appointments at Boğaziçi, Brown, Princeton and Paris VI Universities, the Max-Planck Institute in Göttingen and the Royal Institute of Technology in Stockholm. He received the Junior Scientist Award and the Science Award of the National Research Council, the Information Age Award of the Ministry of Culture and was elected to the National Academy of Sciences of Turkey. Attila Asskar received his engineering diploma from Istanbul Technical University in 1966 and his PhD from Princeton University in 1969.

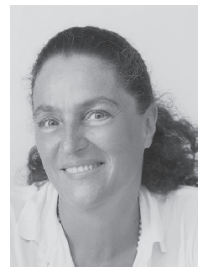

Betül Tanbay is the first woman president of the Turkish Mathematical Society and a professor in functional analysis at Boğaziçi University in Istanbul, where she has served as senate member, vice-provost for foreign affairs and chairwoman. She has held visiting positions at the Universities of California, Santa Barbara and Berkeley, Kansas, Pennsylvania State, Paris VI and Bordeaux. She was founder and first codirector of the Istanbul Center for Mathematical Sciences, a member of the executive and advisory boards of the Feza Gürsey Institute, a scientific council member of IméRA, a project director of the doctoral and postdoctoral network grants of the National Research Council, a committee member of IMU-CWM, EMS-Raising Public Awareness, EMS-Ethics and currently EMS-Executive. Betül Tanbay received her undergraduate degree from ULP, Strasbourg, in 1982 and graduate degrees from UC Berkeley in 1989. 